\title{
KLASIFIKASI MASYARAKAT MISKIN MENGGUNAKAN METODE NAÏVE BAYES
}

\author{
Haditsah Annur \\ haditsah@gmail.com \\ Universitas Ichsan Gorontalo
}

\begin{abstract}
Abstrak
Permasalahan utama dalam upaya pengurangan kemiskinan saat ini terkait dengan adanya fakta bahwa pertumbuhan ekonomi tidak tersebar secara merata. Penelitian akan melakukan klasifikasi berdasarkan data penduduk miskin yang diperoleh dari Kecamatan Tibawa dengan menggunakan teknik data mining. Atribut yang akan digunakan dalam melakukan klasifikasi penduduk adalah Umur, Pendidikan, Pekrjaan, Penghasilan, Tanggungan, Status (Kawin/Belum Kawin). Metode yang akan digunakan adalah metode Naïve Bayes Classifier, yang merupakan salah satu teknik pengklasifikasian dalam data mining. Berdasarkan penelitian yang dilakukan dihasilkan kesimpulan bahwa, Sistem klasifikasi masyarakat miskin di wilayah pemerintahan Kecamatan Tibawa Kab. Gorontalo dapat direkayasa dan Berdasarkan hasil pengujian confussion matrix dengan teknik split validasi, penggunaan metode klasifikasi naïve bayes terhadap dataset yang telah diambil pada objek penelitian diperoleh tingkat akurasi sebesar $73 \%$ atau termasuk dalam kategori Good. Sementara nilai Precision sebesar $92 \%$ dan Recall sebesar $86 \%$.
\end{abstract}

Kata kunci: Tingkat kemiskinan, Data Mining, Klasifikasi, Naïve Bayes

The main problem in the current poverty reduction effort is related to the fact that economic growth is not evenly distributed. The research will classify based on the data of poor people obtained from Tibawa District by using data mining technique. Attributes to be used in classifying the population are Age, Education, Work, Income, Dependent, Status (Married / Unmarried). The method to be used is the Naïve Bayes Classifier method, which is one of the classification techniques in data mining. Based on the research, it is concluded that, the classification system of the poor in the administrative area of Tibawa sub-district, Gorontalo regency can be engineered and Based on the result of confusion matrix testing with split validation technique, the use of naïve Bayes classification method to the dataset which has been taken on the research object obtained the level of accuracy $73 \%$ or included in the Good category. While the Precision value of $92 \%$ and Recall of $86 \%$.

Keywords: Poverty Level, Data Mining, Classification, Naïve Bayes

\section{Pendahuluan}

Semua Masyarakat miskin merupakan suatu kondisi dimana fisik masyarakat yang tidak memiliki akses ke prasarana dan sarana daser lingkungan yang memadai, dengan kualitas perumahan dan pemukiman yang jauh dibawah standar kelayakan serta mata pencaharian yant tidak menentu yang mencakup serluruh mulitidimensi. Penggolongan kemikskinan didasarkan pada suatu standart tertentu yaitu dengan membandingkan tingkat pendapatan orang atau keluarga dengan tingkat pendapatan yang diperlukan untuk memenuhi kebutuhan pokok minimum [1]. Wilayah Kecamatan Tibawa yang terbagi ke dalam 16 Desa, dan Kecamatan Tibawa termasuk Kecamatan yang memiliki penduduk yang masih di bawah taraf hidupnya, yang biasa dikatakan masyarakat miskin. Berdasarkan data masyarakat miskin yang peroleh dari Kecamatan Tibawa Kabupaten Gorontalo yaitu sebagai berikut :

Tabel 1. Data Penduduk Miskin

\begin{tabular}{|c|c|}
\hline Tahun & Jumlah Penduduk Miskin \\
\hline 2015 & 2790 \\
\hline 2014 & 2819 \\
\hline 2013 & 2950 \\
\hline
\end{tabular}

Sumber : Kecamatan Tibawa 
Permasalahan utama dalam upaya pengurangan kemiskinan saat ini terkait dengan adanya fakta bahwa pertumbuhan ekonomi tidak tersebar secara merata di seluruh wilayah Indonesia, khususnya di Kecamatan Tibawa, ini dibuktikan dengan tingginya perbedaan pendapatan antar daerah. Selain itu kemiskinan juga merupakan sebuah hubungan sebab akibat (kausalitas melingkar) artinya tingkat kemiskinan yang tinggi terjadi karena rendahnya pendapatan perkapita, pendapatan perkapita yang rendah terjadi karena investasi perkapita yang juga rendah [2]. Salah satu metode Data Mining yang bisa digunakan adalah Association rule discovery merupakan tugas yang sama dalam data mining, dengan pengecualian bahwa tujuan utama dari klasifikasi adalah prediksi label kelas, sedangkan asosiasi aturan penemuan menggambarkan korelasi antara item dalam database transaksional [3]. Metode yang akan digunakan adalah metode Naïve Bayes Classifier, yang merupakan salah satu teknik pengklasifikasian dalam data mining [4]. Dimana akan dilakukan analisis untuk memperoleh informasi terhadap data lama tingkat kemiskinan. Diharapkan dari penelitian yang dilakukan terhadap sampel data penduduk miskin tersebut dapat diperoleh suatu informasi yang bisa membantu pihak kecamatan untuk merancang strategi dalam meningkatkan kesejahteraan masyarakat. Penelitian akan membuat aplikasi klasifikasi berdasarkan data penduduk miskin yang diperoleh dari Kecematan Tibawa tahun 2015 dengan menggunakan teknik data mining. Variabel inputan yang akan digunakan dalam melakukan klasifikasi penduduk miskin tahun 2016 adalah Umur, Pendidikan, Pekerjaan, Penghasilan, Tanggungan, Status (Kawin/Belum Kawin), sesuai data yang telah diambil dan sesuai dengan variabel yang akan diinputkan, maka hasil klasifikasinya nanti akan menentukan tingkat kemiskinan seperti : Miskin dan Tidak Miskin. Rumusan Masalah penelitian ini adalah menentukan cara merekayasa sistem untuk klasifikasi masyarakat miskin Menggunakan Algoritma Naive Bayes dan Hasil penerapan Algoritma Naive Bayes untuk klasifikasi masyarakat miskin di kecamatan tibawa. Adapun tujuan dari penelitian ini adalah : Klasifikasi masyarakat miskin di Kecamatan Tibawa Menggunakan Algoritma Naive Bayes dan Menerapkan Algoritma Naïve Bayes klasifikasi masyarakat miskin di Kecamatan Tibawa.

\section{Metode}

\subsection{Klasifikasi}

Proses penemuan model (atau fungsi) yang menggambarkan dan membedakan kelas data atau konsep yang bertujuan agar bisa digunakan untuk memprediksi kelas dari objek yang label kelasnya tidak diketahui [5]. Algoritma klasifikasi yang banyak digunakan secara luas, yaitu Decision/classification trees, Bayesian classifiers/ Naïve Bayes classifiers, Neural networks, Analisa Statistik, Algoritma Genetika, Rough sets, k-nearest neighbor, Metode Rule Based, Memory based reasoning, dan Support vector machines (SVM) [6].

\subsection{Algoritma Naïve Bayes}

Bayesian classification adalah pengklasifikasian statistik yang dapat digunakan untuk memprediski probabilitas keanggotaan suatu class. Bayesian classification didasarkan pada teorema Bayes yang memiliki kemampuan klasifikasi serupa dengan decesion tree dan neural network. Bayesian classification terbukti memiliki akurasai dan kecepatan yang tinggi saat diaplikasikan ke dalam database dengan data yang besar [7]. Metode Bayes merupakan pendekatan statistic untuk melakukan inferensi induksi pada persoalan klasifikasi. Pertama kali dibahas terlebih dahulu tentang konsep dasar dan definisi pada Teorema Bayes, kemudian menggunkan teorema ini untuk melakukan klasifikasi dalam Data Mining.Teorema Bayes memiliki bentuk umum sebagai berikut :

$$
P(H \mid X)=\frac{P(X \mid H) P(H)}{P(X)}
$$

Keterangan :

$$
\begin{array}{ll}
\mathrm{X} & =\text { Data dengan class yang belum diketahui } \\
\mathrm{H} & =\text { Hipotesis data } X \text { merupakan suatu class spesifik } \\
\mathrm{P}(\mathrm{H} \mid \mathrm{X}) & =\text { Probabilitas hipotesis } \mathrm{H} \text { berdasarkan kondisi } \mathrm{X} \text { (posteriori prob.) } \\
\mathrm{P}(\mathrm{H}) & =\text { Probabilitas hipotesis } \mathrm{H} \text { (prior prob.) } \\
\mathrm{P}(\mathrm{X} \mid \mathrm{H}) & =\text { Probabilitas } \mathrm{X} \text { berdasarkan kondisi tersebut } \\
\mathrm{P}(\mathrm{X}) & =\text { Probabilitas dari } X
\end{array}
$$




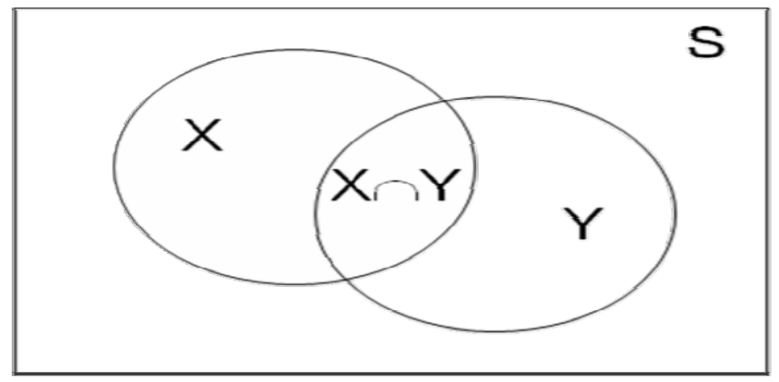

Gambar 1. Teorema Bayes

\section{Hasil dan Pembahasan}

\subsection{Manual Penggunaan Metode Klasifikasi}

Klasifikasi dengan Naïve Bayes Menggunakan Data Latih

Berdasarkan dataset/data latih, maka akan dilakukan proses klasifikasi terhadap data baru berikut :

Umur = Tua

Status = Kawin

Pendidikan $=$ SLTP

Tanggungan $=1$ Orang

Pekerjaan $=$ Pedagang

Penghasilan $=$ Tinggi

Proses naïve bayes

Probabilitas Kelas Miskin :

$P($ Miskin $)=145 / 171=0.847$

Probabilitas Kelas Tidak Miskin :

$\mathrm{P}($ Tidak Miskin $)=26 / 171=0.152$

Menghitung kemungkinan termasuk kategori miskin :

$\mathrm{P}($ Class. Miskin | Umur. Tua $)=86 / 145=0.59$

$\mathrm{P}($ Class. Miskin | Status. Kawin $)=122 / 145=0.84$

$\mathrm{P}($ Class. Miskin | Pendidikan.SLTP $)=121 / 145=0.83$

$\mathrm{P}($ Class. Miskin | Tanggungan.1 Org $)=19 / 145=0.13$

$\mathrm{P}($ Class. Miskin | Pekerjaan.Pedagang $)=1 / 145=0.006$

$\mathrm{P}($ Class. Miskin | Penghasilan. Tinggi $)=0 / 145=0$

Maka kemungkinan termasuk kategori miskin adalah

Class. Miskin $=0.847 \times 0.59 \times 0.84 \times 0.83 \times 0.13 \times 0.006 \times 0$

Class. Miskin $=0$

Menghitung kemungkinan termasuk kategori tidak miskin :

$\mathrm{P}($ Class. Tidak Miskin | Umur, Tua $)=13 / 26=0.5$

$\mathrm{P}($ Class. Tidak Miskin | Status. Kawin $)=20 / 26=0.77$

$\mathrm{P}($ Class. Tidak Miskin | Pendidikan.SLTP $)=3 / 26=0.11$

$\mathrm{P}($ Class. Tidak Miskin | Tanggungan. 1 Org $)=2 / 26=0.08$

$\mathrm{P}($ Class. Tidak Miskin | Pekerjaan.Pedagang $)=4 / 26=0.15$

$\mathrm{P}$ (Class. Tidak Miskin | Penghasilan. Tinggi $)=8 / 26=0.31$

Maka kemungkinan termasuk kategori tidak miskin :

Class. Tidak Miskin $=0.152 \times 0.5 \times 0.77 \times 0.11 \times 0.08 \times 0.15 \times 0.31$

Class. Tidak Miskin $=0.00023$

Karena nilai probabilitas Class.Miskin lebih kecil dari nilai probabilitas Class.Tidak Miskin, maka dapat disimpulkan bahwa data baru diatas termasuk dalam kategori TIDAK MISKIN

\subsection{Pengujian Metode Klasifikasi Menggunakan Data Testing}

1. Adapun pengujian terhadap metode klasifikasi naïve bayes yang digunakan, dilakukan dengan menggunakan teknik split validation dengan confussion matrix, dimana dataset yang disajikan diatas akan dibagi kedalam dua bagian yakni 90\% (171 record) dari dataset akan dijadikan sebagai data training atau latih dan 10\% (19 record) sisanya akan dijadikan sebagai data testing atau uji. 
2. Hasil proses klasifikasi menggunakan metode naïve bayes pada data testing yang berjumlah 19 record dihasilkan proses klasifikasinya sebagai berikut :

Tabel 2. Hasil Klasifikasi Data Testing

\begin{tabular}{|c|c|c|c|c|c|c|c|c|}
\hline id & Umur & Status & $\begin{array}{c}\text { Pendidika } \\
n\end{array}$ & $\begin{array}{l}\text { Tangg } \\
\text { ungan }\end{array}$ & Pekerjaan & $\begin{array}{c}\text { Pengha } \\
\text { silan }\end{array}$ & $\begin{array}{l}\text { Actual } \\
\text { Class }\end{array}$ & $\begin{array}{c}\text { Predicted } \\
\text { Class }\end{array}$ \\
\hline 1 & Tua & Kawin & SLTP & 1 & Pedagang & Tinggi & $\begin{array}{c}\text { TIDAK } \\
\text { MISKIN }\end{array}$ & $\begin{array}{c}\text { TIDAK } \\
\text { MISKIN }\end{array}$ \\
\hline 2 & Muda & $\begin{array}{l}\text { Belum } \\
\text { Kawin }\end{array}$ & SD & 0 & $\begin{array}{l}\text { Buruh } \\
\text { Lepas }\end{array}$ & Rendah & MISKIN & MISKIN \\
\hline 3 & Tua & Kawin & Sarjana & 3 & $\begin{array}{l}\text { Aparatur } \\
\text { Negara }\end{array}$ & Tinggi & $\begin{array}{c}\text { TIDAK } \\
\text { MISKIN } \\
\end{array}$ & $\begin{array}{c}\text { TIDAK } \\
\text { MISKIN } \\
\end{array}$ \\
\hline 4 & Tua & Kawin & SLTP & 4 & Petani & Rendah & MISKIN & MISKIN \\
\hline 5 & Muda & Kawin & Sarjana & 4 & $\begin{array}{l}\text { Aparatur } \\
\text { Negara }\end{array}$ & Tinggi & $\begin{array}{c}\text { TIDAK } \\
\text { MISKIN }\end{array}$ & $\begin{array}{l}\text { TIDAK } \\
\text { MISKIN }\end{array}$ \\
\hline 6 & Muda & Kawin & SD & 3 & Petani & Rendah & MISKIN & MISKIN \\
\hline 7 & Muda & Kawin & $\begin{array}{c}\text { Tidak } \\
\text { Sekolah }\end{array}$ & 2 & Petani & Sedang & MISKIN & $\begin{array}{c}\text { TIDAK } \\
\text { MISKIN }\end{array}$ \\
\hline 8 & Tua & Kawin & SLTP & 3 & $\begin{array}{l}\text { Buruh } \\
\text { Lepas }\end{array}$ & Rendah & MISKIN & MISKIN \\
\hline 9 & Tua & Cerai & SLTA & 2 & Tiada & Tiada & MISKIN & MISKIN \\
\hline 10 & Muda & Kawin & SD & 3 & Petani & Rendah & MISKIN & MISKIN \\
\hline 11 & Muda & Kawin & SLTP & 3 & Petani & Sedang & $\begin{array}{c}\text { TIDAK } \\
\text { MISKIN } \\
\end{array}$ & $\begin{array}{c}\text { TIDAK } \\
\text { MISKIN } \\
\end{array}$ \\
\hline 12 & Muda & $\begin{array}{l}\text { Belum } \\
\text { Kawin }\end{array}$ & SD & 0 & $\begin{array}{l}\text { Buruh } \\
\text { Lepas }\end{array}$ & Rendah & $\begin{array}{c}\text { TIDAK } \\
\text { MISKIN }\end{array}$ & MISKIN \\
\hline 13 & Tua & Kawin & SD & 1 & Tiada & Tiada & MISKIN & MISKIN \\
\hline 14 & Muda & Kawin & SD & 3 & $\begin{array}{l}\text { Buruh } \\
\text { Lepas }\end{array}$ & Rendah & MISKIN & MISKIN \\
\hline 15 & Muda & Kawin & SD & 5 & Petani & Sedang & MISKIN & $\begin{array}{c}\text { TIDAK } \\
\text { MISKIN } \\
\end{array}$ \\
\hline 16 & Tua & Kawin & SD & 3 & Petani & Rendah & MISKIN & MISKIN \\
\hline 17 & Tua & Cerai & SLTA & 1 & Tiada & Tiada & MISKIN & MISKIN \\
\hline 18 & Tua & Cerai & SD & 2 & Tiada & Tiada & MISKIN & MISKIN \\
\hline 19 & Tua & Kawin & SD & 3 & $\begin{array}{l}\text { Buruh } \\
\text { Lepas }\end{array}$ & Rendah & MISKIN & MISKIN \\
\hline
\end{tabular}

Dari hasil proses klasifikasi yang disajikan pada tabel diatas maka dapat dikonversi kedalam bentuk tabel confussion matrix seperti dibawah :

Tabel 3. Pengujian Confussion Matrix

\begin{tabular}{|l|c|c|c|}
\cline { 2 - 4 } \multicolumn{1}{c|}{19 Record } & Tidak Miskin & Miskin & 5 \\
\hline Actual: Tidak Miskin & 4 & 1 & 14 \\
\hline Actual: Miskin & 2 & 12 & \multicolumn{1}{c|}{} \\
\cline { 2 - 4 } & 6 & 13 &
\end{tabular}

Berdasarkan tabel conffussion matrix diatas maka kinerja dari penggunaan metode klasifikasi naïve bayes dapat diukur dengan menghitung nilai accurasi, precision dan recall.

$$
\begin{gathered}
\text { Accuracy } \quad:(\text { TP }+ \text { TN }) / \text { Total } \\
:(12+4) / 19=73 \% \\
\text { Precision }: \text { TP } / \text { Predicted Miskin } \\
: 13 / 13=92 \% \\
\text { Recall }: \text { TP } / \text { Actual Miskin } \\
: 12 / 14=86 \%
\end{gathered}
$$




\subsection{Hasil Klasifikasi pada Sistem}

Form di bawah ini menunjukkan Hasil akhir dari sistem, yang merupakan hasil klasifikasi pada setiap objek dengan menggunakan metode yang diusulkan, pada halaman ini juga nantinya dapat dilakukan proses pencetakan dari hasil klasifikasi tersebut sebagai bahan laporan kepada pimpinan/yang membutuhkan hasil klasifikasi tersebut.

\begin{tabular}{|llllllll}
\hline \multicolumn{1}{c}{ ID } & Umur & \multicolumn{2}{c}{ Status } & Pendidikan & Tanggungan & Pekerjaan & \multicolumn{1}{c}{ Penghasilan } \\
\hline 1 & Tua & Kawin & SD & 2 & Petani & Rendah & MISKIN \\
\hline 2 & Muda & Kawin & SD & 3 & Buruh Lepas & Rendah & MISKIN \\
\hline 3 & Muda & Kawin & SD & 2 & Buruh Lepas & Rendah & MISKIN \\
\hline 4 & Tua & Kawin & SD & 3 & Buruh Lepas & Sedang & TIDAK MISKIN \\
\hline 5 & Muda & Kawin & SD & 3 & Petani & Sedang & TIDAK MISKIN \\
\hline 6 & Tua & Kawin & SD & 4 & Buruh Lepas & Rendah & MISKIN \\
\hline 7 & Tua & Kawin & SD & 2 & Petani & Rendah & MISKIN
\end{tabular}

Gambar 2. Halaman Hasil Klasifikasi

\subsection{Pengujian Black-Box}

\begin{tabular}{|c|c|c|c|}
\hline Input event & Funasi & Hasil sistem & Hasil uii \\
\hline Klik menu kelas & $\begin{array}{l}\text { Untuk menampilkan form } \\
\text { input kelas }\end{array}$ & $\begin{array}{l}\text { Ditampilkan form input } \\
\text { kelas }\end{array}$ & Sesuai \\
\hline Klik menu parameter & $\begin{array}{l}\text { Untuk menampilkan form } \\
\text { input parameter / atribut }\end{array}$ & $\begin{array}{l}\text { Ditampilkan form input } \\
\text { parameter / atribut }\end{array}$ & Sesuai \\
\hline $\begin{array}{l}\text { Klik menu sub } \\
\text { parameter }\end{array}$ & $\begin{array}{l}\text { Untuk menampilkan form } \\
\text { input sub parameter }\end{array}$ & $\begin{array}{l}\text { Ditampilkan form input } \\
\text { sub parameter }\end{array}$ & Sesuai \\
\hline Klik menu training & $\begin{array}{l}\text { Untuk menampilkan form } \\
\text { input data latih / training }\end{array}$ & $\begin{array}{l}\text { Ditampilkan form input } \\
\text { data latih / training }\end{array}$ & Sesuai \\
\hline Klik menu objek & $\begin{array}{l}\text { Untuk menampilkan form } \\
\text { input objek }\end{array}$ & $\begin{array}{l}\text { Ditampilkan form input } \\
\text { objek }\end{array}$ & Sesuai \\
\hline $\begin{array}{l}\text { Klik menu hasil } \\
\text { Klasifikasi }\end{array}$ & $\begin{array}{l}\text { Untuk menampilkan hasil } \\
\text { Klasifikasi keseluruhan } \\
\text { objek }\end{array}$ & $\begin{array}{lr}\text { Ditampilkan } & \text { hasil } \\
\text { Klasifikasi } & \text { keseluruhan } \\
\text { objek } & \end{array}$ & Sesuai \\
\hline $\begin{array}{l}\text { Beri masukan pada } \\
\text { form kelas dan klik } \\
\text { tombol simpan/save }\end{array}$ & $\begin{array}{l}\text { Untuk menyimpan data } \\
\text { kelas yang diketikkan } \\
\text { pada database }\end{array}$ & $\begin{array}{l}\text { Data kelas disimpan } \\
\text { kedalam database }\end{array}$ & Sesuai \\
\hline $\begin{array}{l}\text { Klik tombol tambah } \\
\text { pada data objek }\end{array}$ & $\begin{array}{l}\text { Untuk menampilkan form } \\
\text { input data fakta / uji pada } \\
\text { objek yang dimaksudkan }\end{array}$ & $\begin{array}{l}\text { Ditampilkan form input } \\
\text { data latih }\end{array}$ & Sesuai \\
\hline $\begin{array}{l}\text { Diberi masukan pada } \\
\text { form input data latih } \\
\text { dan klik tombol } \\
\text { simpan/save }\end{array}$ & $\begin{array}{l}\text { Untuk menyimpan data } \\
\text { fakta/uji untuk objek } \\
\text { tersebut }\end{array}$ & $\begin{array}{l}\text { Data fakta/uji disimpan } \\
\text { kedalam database }\end{array}$ & Sesuai \\
\hline
\end{tabular}

\section{Kesimpulan dan Saran}

\subsection{Kesimpulan}

1. Sistem klasifikasi masyarakat miskin di wilayah pemerintahan Kab. Gorontalo dapat direkayasa, hal tersebut dapat dibuktikan melalui interface yang disajikan dan sistem yang telah direkayasa sudah dilakukan pengujian sistem dengan menggunakan whitebox untuk memeriksan alur logika yang digunakan pada sistem dan juga telah dilakukan pengujian blackbox untuk memeriksa kesesuaian fungsi pada setiap interface yang ada.

2. Berdasarkan hasil pengujian confussion matrix dengan teknik split validasi, penggunaan metode klasifikasi naïve bayes terhadap dataset yang telah diambil pada objek penelitian diperoleh tingkat akurasi sebesar $73 \%$ atau termasuk dalam kategori Good. Sementara nilai Precision sebesar $92 \%$ dan Recall sebesar $86 \%$. Berdasarkan hal tersebut dapat dinyatakan bahwa sistem klasifikasi yang dibangun dapat gunakan sebagai bahan masukan bagi pengambil keputusan 


\subsection{Saran}

1. Mengingat nilai akurasi masih berada pada angka $73 \%$, maka masih sangat dimungkin untuk dapat dilakukan penelitian selanjutnya untuk meningkatkan nilai akurasi dengan menambahkan fitur seleksi atau penggunaan Algoritma komputer yang lain.

2. Pada penelitian lain diharapkan dapat digunakan dataset dalam jumlah yang lebih besar atau dengan sejumlah variabel lainnya guna meningkatkan performa dari metode yang digunakan.

\section{Terima Kasih}

Terwujudnya publikasi karya ilmiah ini tidak lepas dari bantuan berbagai pihak,yang telah memberikan dana penelitian melalui Hibah Penelitian Kompetitif di lingkungan Universitas Ichsan Gorontalo, oleh karena itu penulis mengucapkan terima kasih yang sebesar-besarnya kepada : Ketua Yayasan PIPT Ichsan Gorontalo, Rektor Universitas Ichsan Gorontalo, Ketua Lembaga Penelitian Unisan Gorontalo dan Sekretaris Lemlit Unisan Gorontalo. Semoga hasil publikasi karya ilmiah ini, dapat bermanfaat bagi peneliti dan masyarakat.

\section{Daftar Pustaka}

[1] Sumanta, Jaka. 2005. Fenomena lingkaran kemiskinan di Indonesia : Analisis ekonometri regional data panel propinsi tahun 1999-2002. MPKP UI.

[2] Suryawati. 2004. Teori Ekonomi Mikro. UPP. AMP YKPN. Yogyakarta

[3] Ayub, Mewati. (2007). "Proses Data Mining dalam Sistem Pembelajaran Berbantuan Komputer", Jurnal Sistem Informasi Vol. 2 No. 1 Maret $2007: 21-30$

[4] Mustafa , Muhammad Syukri . Simpen, I Wayan. (2014). Perancangan Aplikasi Prediksi Kelulusan Tepat Waktu Bagi Mahasiswa Baru Dengan Teknik Data Mining (Studi Kasus: Data Akademik Mahasiswa STMIK Dipanegara Makassar), ISSN: 2354-5771

[5] Kursini, Luthfi, E. T., 2009, Algoritma Data Mining, Andi Offset, Yogyakarta.

[6] Jananto, Arief. 2013. Algoritma Naive Bayes untuk Mencari Perkiraan Waktu Studi Mahasiswa.

[7] Supriyanto, Catur. Purnama Parida. 2013. deteksi penyakit diabetes type ii dengan naive bayes berbasis particle swarm optimization. Jurnal Teknologi Informasi, Volume 9 Nomor 2, Oktober 2013

[8] Kusumadewi, Sri dkk. 2006. Fuzzy Multi Attribute Decison Making (FMADM). Yogyakarta.Graha IImu.

[9] Bambang Hariyanto, (2004), Sistem Manajemen Basis Data, Informatika, Bandung

[10] Jeffry, L. Whitten,et al. 2004. Metode Desain dan Analisis Sistem. Edisi I. Diterjemahkan oleh tim penerjemah ANDI. Yogyakarta: Penerbit Andi Madcoms.

[11] Jogiyanto, HM.,2005, Analisis dan Desain Sistem Informasi : PendekatanTerstruktur Teori dan Praktek Aplikasi Bisnis, Yogyakarta : Andi 